NBSIR 82-2490 (NBS)

\title{
An Introduction to Chemiluminescence Methods for Lubricant Oxidation Studies
}

U.S. DEPARTMENT OF COMMERCE

National Bureau of Standards

National Measurement Laboratory

Center for Materials Science

Materials Chemistry Division

Washington, DC 20234

April 1982

Interim Report for Period

March 19, 1981-March 31, 1982

Prepared for

U.S. DEPARTMENT OF COMMERCE

National Bureau of Standards - QC__ of Recycled Materials

100 :led Oil Program

.1456 ington, DC 20234 



\section{AN INTRODUCTION TO}

CHEMILUMINESCENCE METHODS FOR LUBRICANT OXIDATION STUDIES

D.B. Clark, S.J. Weeks, and S.M. Hsu

U.S. DEPARTMENT OF COMMERCE

National Bureau of Standards

National Measurement Laboratory

Center for Materials Science

Materials Chemistry Division

Washington, DC 20234

April 1982

Interim Report for Period

March 19, 1981 -March 31, 1982

Prepared for

U.S. DEPARTMENT OF COMMERCE

National Bureau of Standards

Office of Recycled Materials

Recycled Oil Program

Washington, DC 20234

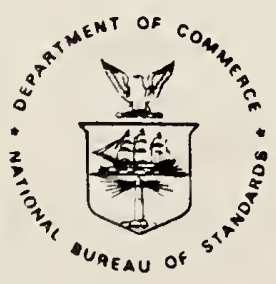

U.S. DEPARTMENT OF COMMERCE, Malcolm Baldrige, Secretary 

An Introduction to Chemiluminescence Methods for Lubricant Oxidation Studies

D. B. Clark, S. J. Weeks, and S. M. Hsu

Materials Chemistry Division

Center for Materials Science

National Bureau of Standards

Washington, D.C. 20234

\section{Introduction}

Chemiluminescence $(C L)$, light produced as a result of a chemical reaction, is a valuable but under-utilized tool for the study of oxidation of fuels and lubricants. Although a large amount of $\mathrm{CL}$ research has been conducted on simple hydrocarbon systems, the extension of that work to complex mixtures, such as lubricating oils, has been slow and rather limited.

Hydrocarbon oxidation produces chemiluminescence in the principal termination reaction, recombination of peroxy radicals. The light intensity is proportional to the rate of that reaction and can be related through various methods to many of the other kinetic parameters of the overall oxidation reaction scheme. $C L$ measurement is a sensitive, non-intrusive method that can provide a continuous monitoring of the reaction. These advantages can be extremely valuable over conventional methods for theoretical and practical studies.

This review will focus primarily on the application of $C L$ in the study of fuel and lubricant oxidation, an area of significant practical importance. A brief discussion of the origin and mechanism of $\mathrm{CL}$ in hydrocarbon oxidation will be followed by a summary of some of the methods which have been developed for the determination of various kinetic parameters. This will be followed by a review of the instrumentation and the applications that relate to fuel and lubricant oxidation studies. 
Several reviews [1-15] on the general topics of chemiluminescence are listed in Table 1. Hydrocarbon oxidation is covered in references [9] and $[16]$.

\section{Mechanism}

The source of chemiluminescence in hydrocarbon oxidation is fairly well established, although the exact mechanism is not completely understood. Hydrocarbon oxidation occurs in a chain reaction generally following the simplified scheme shown below:

$$
\begin{array}{ll}
\text { Initiation } & \begin{array}{l}
\mathrm{RH} \stackrel{\mathrm{O}_{2}}{\longrightarrow} \mathrm{R} \cdot \\
\text { Propagation }
\end{array} \\
\text { Branching } & \begin{array}{l}
\mathrm{R} \cdot+\mathrm{O}_{2} \longrightarrow \mathrm{RO}_{2} \cdot \\
\mathrm{RO}_{2} \cdot+\mathrm{RH} \longrightarrow \mathrm{ROOH}+\mathrm{R} \cdot \\
\mathrm{ROOH} \longrightarrow \text { products }
\end{array} \\
\text { Termination } & \left\{\begin{array}{l}
\mathrm{R} \cdot+\mathrm{R} \cdot \longrightarrow \text { Products } \\
\mathrm{RO}_{2} \cdot+\mathrm{R} \cdot \mathrm{OH} \\
\mathrm{RO}_{2} \cdot+\mathrm{RO}_{2} \cdot \longrightarrow \text { products }
\end{array}\right.
\end{array}
$$

Where $\mathrm{RH}$ is the hydrocarbon, and $\mathrm{R} \cdot$ and $\mathrm{RO}_{2}$ - are the alkyl and peroxy radicals, respectively.

Chemiluminescence is believed to arise from reaction (7), the recombination or disproportionation of peroxy radicals $[14,17]$ by the Russell termination reaction. This is the only reaction of the set that has sufficient energy to emit visible light. The reaction can be written in more detail as:

$$
\mathrm{RO}_{2} \cdot+\mathrm{RO}_{2} \cdot \longrightarrow \mathrm{RO}^{*}+\mathrm{ROH}+\mathrm{O}_{2}
$$

where the products are an excited state ketone RO*, an alcohol ROH, and molecular oxygen. The excited state ketone can relax to the ground state with the emission of light producing chemiluminescence, 


$$
\mathrm{RO}^{*} \longrightarrow \mathrm{RO}+\mathrm{hu} .
$$

The emission spectrum is equivalent to the fluorescence spectrum of the molecule.

The effective quantum efficiency for light emission is generally quite low, on the order of $10^{-7}$ to $10^{-10}$ [18]. This low yield is an effect of the low luminescence efficiency and may also be due in part to a low excitation efficiency in reaction $(7),[19,20]$. The low luminescence efficiency is caused by deactivation of the excited species by subsequent secondary physical processes such as intermolecular energy transfer and collisional quenching by oxygen or other solution components,

$$
\begin{gathered}
\mathrm{RO}^{*}+\mathrm{M} \longrightarrow \mathrm{RO}+\mathrm{M}^{*} \\
\mathrm{M}^{*} \longrightarrow \mathrm{M}
\end{gathered}
$$

where $M$ is the quenching component, as well as by radiationless intramolecular transitions,

$$
\mathrm{RO}^{*} \longrightarrow \mathrm{RO} \text {. }
$$

The apparent efficiency is also affected by absorption of the light by the reaction mixture. These secondary physical effects and the excitation and emission processes are discussed in greater detail in several reviews $[3,4,13]$.

The intensity of chemiluminescence measured in photons per unit time is proportional to the rate of reaction (7), $w_{7}$, or equivalently through the rate equation to the square of the peroxy radical concentration $\left[\mathrm{RO}_{2} \cdot\right]^{2}$,

$$
\mathrm{I}_{\mathrm{CL}}=\mathrm{C}_{1} \mathrm{~W}_{7}=\frac{-\mathrm{d}\left[\mathrm{RO}_{2} \cdot\right]}{\mathrm{dt}}=\mathrm{k}_{7}\left[\mathrm{RO}_{2} \cdot\right]^{2}
$$


The proportionality constant $C_{1}$, essentially equal to the effective quantum efficiency for emission, is in general unknown and unmeasurable, except in the case of simple hydrocarbon systems [14]. In complex systems, the proportionality constant will vary with the composition and concentration of the reactants since the rate constant and excitation efficiency of reaction (7) depend strongly on the structure of the two combining peroxy radicals [21,22]. It will also vary with the composition of the entire system, reactants, products, solvents, dissolved gases, etc., since any of these can influence the secondary physical processes that lead to de-excitation without light emission. Thus, the reaction rate or peroxy radical concentration cannot be determined quantitatively directly from the light intensity. However, these and several other important kinetic parameters can be determined from relative values of light intensity by some of the methods described in the next section.

The effective quantum efficiency can be improved by adding energy acceptors to the reaction mixture. These are substances to which the excited state reaction products can efficiently transfer energy, and which have a higher quantum efficiency for subsequent emission of light. This process, known as sensitized luminescence, is described by the following reactions:

$$
\begin{array}{r}
R 0^{*}+A \longrightarrow R O+A^{*} \\
A^{*} \longrightarrow A+h v
\end{array}
$$

where $A$ is the acceptor molecule. In general, the acceptor molecule is less sensitive to quenching because it has a much shorter radiative lifetime than the original excited species. The observed emission spectrum will be shifted to that of the energy acceptor. To be effective, the acceptor must not otherwise participate in the reaction. Vasil'ev and co-workers have studied the use of anthracene derivatives which are commonly used energy acceptors and divided them into "good" and "bad" groups [23]. 


\section{Kinetic Methods}

Chemiluminescence measurements can provide valuable information about hydrocarbon oxidation reactions. However, two important points must be kept in mind in evaluating experimental results $[15,18]$. First, the $C L$ intensity is proportional only to the rate of peroxy radical recombination, reaction (7), and not necessarily to the overall oxidation rate. Second, CL occurs in two stages, excitation and emission, and the efficiency or yield for each of these steps depends on the composition of the reaction mixture. The effective quantum efficiency is, thus, a complex function of composition so that comparisons between samples are not necessarily straightforward. The brightest $C L$ intensity is not necessarily indicative of the fastest oxidation.

This complexity has made empirical approaches popular in chemiluminescence studies of fuels and oils. Several easily measured parameters have been used to compare oils in terms of oxidizability. Probably the least valid, in terms of the above discussion, is a measure of the total intensity of light under the same reaction conditions. More accurate measures are induction time at a constant temperature or onset temperature during a slow temperature scan. In these cases, $C L$ is used basically as a marker for the beginning of significant oxidation rather than as a direct measure of the oxidation rate. The induction time has been used, for example, to rate oxidation inhibitors [24].

A number of more exact methods have been developed for using CL measurements to determine various kinetic parameters of oxidation in simple hydrocarbon systems. The assumptions inherent in these methods are that the reactions are described fairly completely by the scheme shown above and that CL arises from reaction (7) of that scheme. While they were developed for simple hydrocarbons, some of these methods may be applicable to fuels and oils, especially those methods carried out under steady state conditions. 
In the development of many of these methods, the reactions were run with added initiators. Although this is not necessary, it allows more information to be determined, because the initiation rate is then known. Energy acceptor molecules can also improve the measurements by increasing the sensitivity due to increased light output and by minimizing secondary energy transfer processes which may be composition and temperature sensitive.

Some of the methods are described below and are summarized in Table 2. The rate constants refer to the reactions in the original sequence ( 1 to 7 ). General references for the methods are given after each heading.

\subsection{Activation Energy [7,14]}

The temperature dependence of the $\mathrm{CL}$ intensity can be plotted in Arrhenius fashion to give the activation energies for various of the reaction steps. Mendenhal1 [7] shows that under steady-state conditions when oxygen diffusion is rate limiting, a common situation in lubricant studies at high temperatures, the activation energy determined from the $C L$ intensity $E_{C L}$ gives the activation energies for the propagation and termination steps,

or

$$
\begin{aligned}
& E_{C L}=2 E_{\text {prop }}-E_{\text {term }} \\
& E_{\text {prop }}=E_{C L} / 2
\end{aligned}
$$

since the activation energy for termination by radical recombination is essentially zero [15]. Under similar conditions, the activation energy for initiation is given by Arrhenius treatment of $t_{\frac{1}{2}}$, the time to reach half of the steady state intensity after the start of oxidation, as shown in Figure 1.

Under steady state conditions in the presence of sufficient oxygen the initiation and termination rates are equal and termination is essentially al1 by reaction (7). The $\mathrm{CL}$ intensity is then proportional to the initiation rate as well as to the termination rate. Since the activation energy for termination is zero on Arrhenius plot of $\log C L$ intensity versus the reciprocal of 
the absolute temperature then gives the activation energy for the initiation directly [14]. The oxygen supply will be sufficient, that is, not rate limiting, at low temperatures where the reaction rates are slower than the oxygen diffusion rate or in an apparatus designed for optimum diffusion at higher temperatures.

These measurements are more accurate with the use of an energy acceptor because the effect of the temperature dependence of quenching and secondary reactins is greatiy reduced [14].

\section{2 oxygen Drop $[8,14]$}

The oxygen drop method provides a measure of the overall oxidation rate. This method is illustrated by Figure 1 , a curve of $C L$ intensity versus time. Following the initiation of oxidation at point $A$ the intensity increases to reach a maximum value at $B$. At point $C$ the oxygen is shut off and the intensity again increases because of a decrease in quenching of the excited state species by the now decreasing amount of oxygen in the system. The reaction rate, however, is essentially independent of oxygen concentration except at very low levels $[8,16]$ and continues at a constant value to $D$. At $D$ the oxygen in the system has been consumed and the reaction rate and $C L$ intensity drop sharply. This is the "oxygen drop." If the amount of oxygen in the system at point $C$ is known then the time to the oxygen drop gives a direct measure of the oxidation rate. Since the $C L$ intensity is used only as a marker for the end of oxidation, the method is unaffected by secondary physical processes such as quenching and energy transfer. Its accuracy is primarily dependent on the quality of thermostatting in the system [14]. 
It can be shown that [14]

$$
\begin{aligned}
1 / t & =\alpha[\mathrm{RH}]+\beta, \\
\alpha & =k_{3}\left(\frac{w_{i}}{k_{7}}\right)^{\frac{1}{2}}\left[0_{2}\right]_{0}, \\
\beta & =C_{2} w_{i} /\left[0_{2}\right]_{0},
\end{aligned}
$$

where $t$ is the oxygen drop-time, $[\mathrm{RH}]$ and $\left[\mathrm{O}_{2}\right]_{0}$ are the hydrocarbon and initial oxygen concentrations, $w_{i}$ is the initiation rate, and $C_{2}$ is a constant whose value depends on the initiator used. Repetition of the experiment at different hydrocarbon concentrations and plotting the reciprocal of the oxygen drop time, $1 / t$, versus concentration gives the rate constant ratio $k_{3} / k_{7}{ }^{1 / 2}$, and either the initial oxygen concentration or the initiation rate again providing one of those quantities is known. A further extension of the method allows very precise $C L$ measurements of the slope of the oxygen drop to be used to calculate the rate constant ratio $k_{2} / k_{5}{ }^{1 / 2}$ [25].

As originally developed, the oxygen drop method was used in single phase systems, where the only oxygen available was that dissolved in the liquid phase. This could be extended to two-phase liquid-gas systems provided the mass transfer between the phases was not limiting. A system of this type, incorporating both $\mathrm{CL}$ and independent measurements of oxygen consumption, is being developed at the National Bureau of Standards.

\section{3 Non-Steady State Methods $[12,26,27]$}

The above methods imply stationary or steady state reaction kinetics and, in general, give only ratios of rate constants. Absolute values of the rate constants can be obtained by suddenly causing the reaction to enter into a non-stationary state by, for instance, a sudden change in the initiation rate or sudden introduction of oxygen into a chemically initiated system. Changing the 
initiation rate, which can be done by fast introduction of an initiator or abruptly starting or stopping the illumination of a photosensitive initiator, gives $k_{7}$ the termination reaction rate constant. Sudden introduction of oxygen into a system containing hydrocarbon and an initiator gives both $k_{5}$ and $k_{7}$ termination rate constants, since the introduction of oxygen causes a change in termination from reaction (5) to reaction (7). This is also called the oxygen aftereffect method. Rapid heating of the sample has also been studied as a method of inducing non-stationary kinetics [12].

These non-stationary state methods are primarily for use with simple hydrocarbon systems. They may not be applicable to oils or other complex mixtures, since they depend on the rate constants of the six individual reactions not changing with reaction conditions. In a complex mixture, the observed rate constant is an average of the individual rate constants for each hydrocarbon in each step and is a function of composition which will, in general, change with changing reaction conditions.

4. Applications

The potential applications of $C L$ far exceed the number and type of current applications. Because of the sensitivity of the technique and the possibility of relating the $C L$ signals to the chemistry and kinetics of the system involved, $C L$ can be used to evaluate the stability and oxidative capacity of fuels and lubricants in terms of: (1) molecular structural differences, chemical composition, and basestock source; (2) physical properties, such as distillate cut (boiling point range) and viscosity grade; (3) effect of additives and additive type; (4) additive interactions with basestocks and with other additives; (5) formulation of additive packages; (6) effect of processing changes; (7) effect of environment (temperature, atmosphere, contact with other materials, etc.); (8) service life/performance; (9) storage life; and, (10) quality control of processing. 
All of the above focus on the oxidation degradation and reaction mechanisms and allow products to be evaluated from the point of view of their stability (degradation) and performance (failure). In addition, insights into oxidation mechanisms gained in these experiments can be extremely useful in new additive research and in process technology development.

Highlights of the few published or known studies of chemiluminescence in the oxidation of actual fuels and lubricants are presented in Table 3 and will be discussed below. Related basic research on chemiluminescence in simple hydrocarbon systems is summarized in Table 4. Chemiluminescence is particularly useful in studies of oxidation inhibitors and catalysts, both of which will be discussed in later sections.

\subsection{Fuel and Lubricant Studies}

The published studies of $\mathrm{CL}$ in the oxidation of actual fuels and lubricants are limited to three groups. Two groups in the USSR investigated antioxidants in oils and a group in the U.S. studied fuel stability.

Antioxidant Studies. In the USSR, Suleimanova and co-workers [28-33] studied the oxidation stability of paraffin oils and lubricating oil basestocks with and without additives. They developed two standard test procedures [30], a "constant background method" in which the time to reach a constant $\mathrm{CL}$ intensity was determined at each temperature during stepwise heating from 100 to $200^{\circ} \mathrm{C}$ in $10^{\circ}$ steps, and a "constant time method" in which the total $\mathrm{CL}$ signal was measured for $10 \mathrm{~s}$ for each temperature step as before. These methods were used primarily as relative analytical techniques rather than as actual oxidation tests. For instance, the authors observe that 1 ight output from oxidized oils is decreased compared to that from fresh samples. They, therefore, use their procedures to judge the degree of oxidation or degradation of oil samples from standard bench oxidation tests [32] or engine tests [31]. 
This work can be used to illustrate some of the factors that must be considered in developing evaluative $\mathrm{CL}$ test methods. The constant background test is basically a measurement of induction time as a function of temperature. However, when a single $0.2 \mathrm{~cm}^{3}$ sample volume is used for the entire test, the measurements toward the end of the run are being made on a severely oxidized sample. The authors reported that by the end of the tests ( 6 to 14 hours) the oils had been reduced to powders [31].

The constant time method is a much shorter test lasting only $10 \mathrm{~s}$ at each temperature and therefore does not suffer this drawback. Because of its short duration it is the only method of the two used routinely in these studies. The method essentially measures an initial reaction rate and its variation with temperature. The authors used this initial rate method to rank the antioxidant performance of various additives, the lower the light output, the better the additive. However, in the work discussed below, Gol'denberg, Shmulovich, and Yurchenko [39], show that other factors are also important in judging additive effectiveness. The usefulness of these two methods is unknown since Suleimanova presents rankings of several tested additives without comparable data from other tests to support his methods or conclusions [33].

The authors also use both of these methods to rank the oxidative stability of a number of basestocks $[30,33]$. This could also lead to inaccurate results because, as discussed before, $\mathrm{CL}$ intensities should not be used as direct measures of oxidation rates $[12,14,18]$. CL measuremenets should only be used to determine other parameters such as reaction rates, induction times, or activation energies which can then be used for comparison. In general, the CL intensity is proportional only to the rate of the reaction from which the light is produced, not necessarily to the overall oxidation rate $[15,18]$. The proportionality constant is the product of the efficiencies of excitation and emission, both 
of which depend on the sample composition and experimental conditions. For example, lubrication oil basestocks with different physical properties may contain widely different oxygen concentrations in a given oxidation apparatus (especially in tests not designed for optimum control of oxygen diffusion into the sample). As shown before in the discussion of the oxygen drop test, the light emission is very sensitive to oxygen concentration.

Shmulovich and Gol'denberg [24] studied chemically and thermally initiated $\mathrm{CL}$ in paraffin oils over a temperature range from 60 to $190{ }^{\circ} \mathrm{C}$. Generally, azobisisobutyronitrile (AIBN) or a hydroperoxide was introduced into the system to initiate $\mathrm{RO}_{2}$. formation. Dibromoanthracene (DBA) was used as an energy acceptor to enhance the $C L$ signal. A number of different compounds were studied for their antioxidant capabilities. Natural antioxidant concentration and thermal stability of the oils could be determined by measuring the induction period, the time from the beginning of a test to the appearance of a significant increase in the $\mathrm{CL}$ signal. This test was used to rate antioxidants and provided a rapid screening procedure for antioxidant efficiency. The efficiency of a given antioxidant was calculated from an empirical relationship comparing the antioxidant induction time as a function of concentration with that of another antioxidant which had been chosen as a standard. One study roughly correlated the oxidation rate with activity of antioxidants. According to the authors, these studies showed the $\mathrm{CL}$ signal had two components: one due to peroxy radical recombination and the other resulting from accumulation of hydroperoxide reaction products. However, this hypothesis is not generally supported by other investigators $[17]$.

Gol'denberg and Shmulovich later extended this work [37-39], incorporating the theory of Karpukhin and Shlyapintokh [8,34-36] which is discussed in Section 4.3. Using this theory the authors were able to calculate the ratio $k_{8} / k_{7}^{\frac{1}{2}}$ 
where $k_{8}$ [see reaction (18)] and $k_{7}$ are the rate constants for termination by interaction of peroxy radicals with inhibitors and by disproportionation respectively. This ratio was used as a ranking parameter to rate the effectiveness of a number of antioxidants and to determine the concentration of naturally occurring inhibitors. The authors also suggested the possibility of effecting long-term stabilization of oil by using $\mathrm{CL}$ measurements to control subsequent antioxidant addition in service.

Fuel Stability. Mendenhall and Nathan [40-42] at Battelle, were able to predict the service life of JP5 jet fuels using the oxygen drop CL method. A set of $I_{C L}$ vs $t$ curves, at temperatures between 125 and $150^{\circ} \mathrm{C}$ were obtained. The maximum intensity ( $I_{\max }$ in Figure 1 ) and induction period ( $t_{\frac{1}{2}}$ in Figure 1 ) from such temperature variation experiments were used to obtain activation energies from Arrhenius plots. The plots showed that two different propagation mechanisms were occurring, each with its own temperature regime. These results explained why the commonly used accelerated tests did not give accurate indications of fuel stability. The major benefit of $C L$ techniques is that due to their extreme sensitivity they can examine materials under actual use conditions in non-accelerated tests. Several jet fuels were evaluated by the CL techniques. "Bad" fuels were able to be discriminated from "good" fuels.

In an isolated study, Markby and co-workers [43] at the U.S. Bureau of Mines, observed light induced $C L$ of coal derivatives and petroleum asphalts while performing a liquid scintillation experiment. They report their observations and suggest a mechanism for photo-initiated chemiluminescence.

\subsection{Simple Hydrocarbons}

Because of the complexity of real samples, it may be difficult or impossible to accurately extrapolate methods and mechanisms from simple chemical systems. Although quantitative data on individual rate constants cannot be obtained due 
to the multiplicity of reactions and deactivations that can occur; overall rates and other qualitative information can provide much necessary information, as noted above. Basic research studies can provide a better understanding of real situations by elucidating simple mechanisms that combine to form the complex system. Most of the knowledge of the chemiluminescence process that has been described above has been determined from studies of simple systems.

These studies are listed in Table 4. They will not be discussed individually, but many of them have been used in the general discussions of $C L$ in this paper.

\section{3 Oxidation Inhibitors}

Chemiluminescence appears to be a valuable tool for the study of oxidation inhibitors. In general, inhibitors work by reacting with radicals to terminate growing chains and, thus, slow the rate of oxidation. Since the $C L$ intensity is a measure of peroxy radical concentration, inhibitor addition diminishes the intensity in direct proportion to the activity of the inhibitor. At steadystate, the following relation between the oxidation rate, $\mathrm{w}$, and the $\mathrm{CL}$ intensity, I, can be obtained,

$$
\frac{W}{W_{0}}=\left(\frac{I}{I_{0}}\right)^{\frac{1}{2}},
$$

where the subscript, 0 , refers to the uninhibited system [34].

The following set of equations describes the action of an inhibitor and must be added to the previous set, Eqs. (1-7), to complete the reaction scheme for inhibited oxidation:

$$
\begin{aligned}
\mathrm{InH} & +\mathrm{RO}_{2} \cdot \stackrel{\mathrm{K}_{8}}{\longrightarrow} \mathrm{ROOH}+\mathrm{In} \cdot, \\
\mathrm{RO}_{2} \cdot+ & \mathrm{In} \cdot \stackrel{\stackrel{\mathrm{K}_{9}}{\longrightarrow} \text { products },}{ } \\
& 2 \mathrm{In} \cdot \stackrel{\mathrm{k}_{10}}{\longrightarrow} \text { products, }
\end{aligned}
$$


where InH is the inhibitor.

Karpukhin, Shlyapintokh, and co-workers [8,34-36] used this scheme in studying the kinetics of inhibited oxidation in several simple hydrocarbon systems. They showed and confirmed experimentally that to a very good approximation

$$
\left(\frac{I_{0}}{I}\right)^{\frac{1}{2}}=1+1.1 \frac{k_{8}[\mathrm{InH}]_{0}}{\left(k_{7} w_{i}\right)^{\frac{1}{2}}}
$$

where $[\mathrm{InH}]_{0}$ is the initial inhibitor concentration, and $w_{i}$ is the rate of initiation. The parameter $k_{8} /\left(k_{7} w_{i}\right)^{\frac{1}{2}}$ is found from a plot of $\left(I_{0} / I\right)^{\frac{1}{2}}$ versus $[\mathrm{InH}]_{0}$

Another parameter, $k_{8}\left(w_{i} / k_{7}\right)^{\frac{1}{2}}$, found from the slope of the kinetic curve of $I_{1} I_{0}$ versus time, can be combined with this to give individual values for the initiation rate, $w_{i}$, and the rate constant ratio $k_{8} /\left(k_{7}\right)^{\frac{1}{2}}$, which is characteristic of the relative activity of the inhibitor. The kinetic curves which show an increase in intensity as the inhibitor is consumed, are S-shaped with the inflection point at $I / I_{0}=0.55$ [25]. The slope at that point is related to this second parameter by [35]:

$$
\frac{d\left(I / I_{0}\right)}{d t} \max =0.22 k_{8}\left(\frac{w_{i}}{k_{7}}\right)^{\frac{1}{2}}
$$

Use of this method was complicated by the observation that the maximum slope decreases with increasing initial concentration of inhibitor implying a decrease in inhibitor activity with increasing initial concentration. This result, supported by other investigators [44], is suggested as being due to an effect of inhibitor reaction products on the radical concentration [36], perhaps branching due to breaking of peroxide bonds in some of the products. To 
surmount this problem, the data for a number of different initial concentrations were extrapolated to $[\mathrm{InH}]_{0}=0$ to give a concentration independent value for $d\left(I / I_{0}\right) / d t \max _{\text {for }}$ use in the above equation.

Several application-oriented studies have used $\mathrm{CL}$ as a convenient means for rating the relative effectiveness and concentration dependence of initiators. Shlyapintokh [45], using Eq. (17) above, suggested using the reciprocal of the inhibitor concentration that gives a fifty percent decrease in $C L$ intensity as a measure of relative activity. In studies already discussed, Suleimanova and co-workers [28-33] ranked additives by their ability to decrease the absolute $C L$ intensity in a given oil. Shmulovich and Gol'denberg [24] initially used the induction time to rate additives but later extended Karpukhin and Shlyapintokh's theory to these complex materials using $k_{8} /\left(k_{7}\right)^{\frac{1}{2}}$ as a ranking parameter [39].

The inhibitor concentration dependence can also be used to determine the number of chains terminated per molecule of inhibitor and to investigate mechanisms of inhibitor action. Examples of the latter are studies which show that stable nitroxyl radicals terminate chains by reacting only with alkyl radicals and not with peroxy radicals [46], while other inhibitors, like ionol, react exclusively with peroxy radicals. Other studies have looked at synergistic effects from combinations of inhibitors [30].

One final concern in using $C L$ to study inhibition is that some antioxidants, such as phenols, are known deactivators of excited states so that the decrease in $\mathrm{CL}$ intensity could also be due to quenching of the excited species. However, Vasil'ev [47] and others [8] have shown that the quenching effect is negligible in comparison with inhibition. 


\section{4 Metal Catalysts}

$\mathrm{CL}$ is also applicable to studies of catalyzed reactions. However, only a few CL studies of catalyzed hydrocarbon oxidations have been published. Zakharov and Shlyapintokh [48-50] studied the oxidation of ethylbenzene in the presence of cobalt acetate, which catalyzes the reaction by decomposing hydroperoxides to form new radicals. Catalysis increased the steady-state $\mathrm{CL}$ intensity above that of the non-catalyzed reaction; but, except at fairly low concentrations, the intensity was independent of the amount of catalyst. The authors showed that in a system where initiation occurs only by the catalyzed hydroperoxide decomposition, the $\mathrm{CL}$ intensity is proportional to the hydroperoxide concentration and decomposition rate, as well as to the oxidation rate [49]. This allowed measurement of the effective rate constant for decomposition [50] and determination of the mechanism of catalyst action [48] by using non-stationary state techniques. The results agreed very well with a contemporary study of the same reaction by standard methods.

Gol'dberg and Obukhova [51] studied the reaction of manganese stearate with peroxy radicals. Such transition metal salts apparently act as inhibitors under certain conditions $[16,52]$ by donating an electron to a peroxy radical, eliminating the radical, and terminating an oxidation chain. The authors used $\mathrm{CL}$ techniques to determine the rate constant for the reaction and showed that the value was close to corresponding values for the reaction of peroxy radicals with strong inhibitors.

Rychlá-Matisová and co-workers [53] studied CL in the decomposition of 2,2-azobisisobutyronitrile (AIBN) and cumene hydroperoxide catalyzed by bis(-)-ephedrine copper(II) chelate. With AIBN, a commonly used initiator, the copper chelate acts to terminate radicals formed from the initiator, with a resulting decrease in $\mathrm{CL}$. With the hydroperoxide, the chelate acts as an 
accelerator, catalyzing decomposition to form new radicals. This causes an increase in $\mathrm{CL}$. In a real oxidation system, a metal catalyst probably plays both roles, inhibitor and accelerator. The overall effect can be detected and followed by measuring changes in the $C L$ intensity.

\section{Instrumentation}

The basic instrumentation used for $C L$ is spectroscopically quite simple. General reviews $[2,7,10,11]$ of $\mathrm{CL}$ instrumentation are listed in Table 1 .

Figure 2 shows block diagrams of a typical instrumental arrangement. The typical instrument consists of a heated reaction cell in a thermally insulated and lighttight environment. The light emitted due to the oxidation reaction may or may not be spectrally isolated by filters, monochromators, polychromators, or simply by the transmission characteristics of the optics. The light is then detected by a PMT, which may be cooled to decrease the dark noise. The PMT is a phototransducer, whose electrical output can be monitored using an electrometer or photon counter. The signal can then be displayed on a recorder, oscilloscope, or CRT, or may be processed digitally. Commercial instruments are available for bioluminescence studies. However, these would have to be modified for the study of fuels and lubricants. In general, the CL apparatus consists of a special reaction cell combined with a spectrometer or filter photometer. Liquid scintillation counters, spectrofluorimeters, filter fluorimeters, UV-vis spectrophotometers, photometers, and radiometers have all been modified (or assembled) for use in $\mathrm{CL}$ studies. The main instrumental criteria for the study of the weak $\mathrm{CL}$ emitted in the oxidation reactions of fuels and lubricants are: (1) a reaction cell with a viewing port; (2) accurate temperature measurement and control; (3) accurate control of atmosphere and gas $\left(\mathrm{O}_{2}\right)$ introduction to the sample; (4) a "light-tight" optical path; and (5) a sensitive photomultiplier tube (PMT). 
State-of-the-art instrumentation has to consider the reaction cell separately from the spectral readout device. Engine temperatures to which a lubricating oil is subject are as high as 200 to $300{ }^{\circ} \mathrm{C}$. No commercially available cells are made to study condensed phase $C L$ at these high temperatures. However, there are articles $[54,55]$ which describe experimental and theoretical considerations of cell design in analytical chemiluminescence systems. Currently, most researchers use quartz or glass reaction vessels.

Spectrometrically, the most recent innovations consist of the use of image devices, such as photodiode arrays and vidicon tubes or the use of rapid-scan or slew-scan spectrometers. The obvious advantage here is the ability to get much more detailed information on the oxidation reactions occurring. Ingle and co-workers $[56,57]$ have utilized a microprocessorcontrolled intensified diode array to acquire CL spectra. This system is capable of producing a 512 point $\mathrm{CL}$ spectrum from 200 to $840 \mathrm{~nm}$ in as little as four milliseconds and can also signal average. The primary disadvantage of image devices is their lack of sensitivity when compared to PMT. Although the $\mathrm{CL}$ spectra obtained provide principally qualitative information about the $\mathrm{CL}$ reactions, they are useful for (1) choosing PMT's for maximum sensitivity at the wavelengths of maximum $C L$ intensity, (2) identifying reactant or production absorption interferences, (3) elucidating the nature of matrix interferences, or (4) obtaining information about $C L$ reaction mechanisms (e.g., identification of the luminescing species or the change in the species luminescing with time or temperature). Often qualitative information may be sufficient to solve a problem or control a process. The provision of corrected CL spectrum may in itself provide necessary information.

The CL signal is usually assumed to come from the bulk of the solution (homogeneous $\mathrm{CL}$ ) and not to change its spectral distribution. Lloyd and Coworkers [59-61] observed a comparatively strong CL from the reaction(s) occurring 
at the walls of the reaction vessels (heterogeneous $C L$ ) which could easily be mistaken for $\mathrm{CL}$ from the bulk of the solution. They noted that the CL intensities did not vary with volume but did vary with the method used to clean the reaction vessel. The heterogeneous $C L$ was in a different part of the spectrum than the homogeneous $\mathrm{CL}$ and could be minimized under certain conditions. Monitoring the entire spectrum would help to aleviate this problem and also give added insight into changes in reaction types occurring. Often to avoid changes in spectral information, an energy transfer agent will be used. This does not affect the overall oxidation reaction but does enhance the $\mathrm{CL}$ and 1 imit the $\mathrm{CL}$ light output to a specific portion of the spectrum.

In CL studies of fuels and lubricants temperature control, varnish formation, condensation, correct identification of spectral information (e.g., bulk vs surface reaction, or stray light, or changes in spectral composition), and safety are important. Oscillations of the CL intensity have been observed [58] which corresponded to the change in direction of the temperature gradient between the sample and thermostatting equipment. The oscillations were substantially larger than would have been expected if they were solely due to temperature fluctuations. This demonstrates the need for accurate temperature control. Varnish formation is difficult to avoid, and viewing from the bottom of a cell should be done very cautiously. Proper gas flows to control the atmosphere can eliminate condensation along the optical path.

6. Conclusion

Chemiluminescence methods provide an extremely practical means of testing the stability of fuels and lubricants, as well as of selecting additives and studying the oxidation process under conditions similar to those experienced in service. $C L$ methods are nonintrusive and can provide continuous monitoring. The techniques are sensitive so that analyses are rapid, and only require a small 
sample. At present, however, the lack of suitable, commercially available sample cells hinders the technique's use as a routine research tool. A well-designed CL instrument would be a powerful tool to attack the complex problems of fuel and lubricant oxidation. 
References

[1] Gundermann, K. D., "Recent advances in research on the chemiluminescence of organic compounds," Topics in Current Chemistry, 46, (Photochemistry), Springer-Verlag, New York, $1 \overline{974}$.

[2] Heller, C. A., and Richter, H. P., "Chemiluminescence in the condensed phase: Measurement of rates and yields of excited state formation, "Chapter 1 in Creation and Detection of the Excited State, Vol. 3, W. R. Ware, ed. Marcel De kker, NY (1974).

[3] Hercules, D. M., "Physical Basis of Chemiluminescence," in Current Status of Liquid Scintillation Counting, "F. D. Bransome, ed., NY (1970).

[4] McCapra, F., "Chemiluminescence of organic compounds," Prog. in Org. Chem. 8, 231 (1973).

[5] McCapra, F., "Chemiluminescence," Essays in Chemistry, 3, 101 (1972).

[6] McCapra, F., "The chemiluminescence of organic compounds," Pure and Appl. Chem., 24, 611 (1970).

[7] Mendenhal1, G. D., "Analytical applications of chemiluminescence," Angew. Chem. Int. Ed. Engl., 16, 225-232 (1977).

[8] Papisova, V. I., Shlyapintokh, V. Ya., and Vassil'ev, R. F., "Chemiluminescence and the kinetics of chemical reactions," Uspekhi Khimii, 34, 599 (1965).

[9] Reich, L., and Stivala, S. S., Weak chemiluminescence during hydrocarbon autoxidation, Ch. 5 in Autoxidation of Hydrocarbons and Polyolefins, Kinetics, and Mechanisms, Marcel Dekker, Inc., NY (1969).

[10] Seitz, W. R., and Neary, M. P., "Chemiluminescence and Bioluminescence Analysis," Ch. 2. in Contemporary Topics in Analytical and Clinical Chemistry, Vol. 2, Plenum Press, NY (1977).

[11] Shlyapintolsh, V. Ya, Karpukhin, O. N., Postnikov, L. M., Tsepalov, V. F., Vichutinskii, A. A., and Zakharov, I. V., Chemiluminescence Techniques in Chemical Reactions, Consultants Bureau Transl., Plenum Press, NY (1968).

[12] Shlyapintokh, V. Ya., "Free radicals and chemiluminescence," Russ. Chem. Rev., 35, 292 (1966).

[13] Vassil'ev, R. F., "Chemiluminescence excitation mechanisms," Russ. Chem. Rev., 39, 529 (1970).

[14] Vassilev, R. F., Chemiluminescence in Liquid-phase Reaction, Chapter 8 in Progress in Reaction Kinetics, 4, G. Porter, ed. Pergamon Press (1967).

[15] Vassilev, R. F., "Chemiluminescence in solutions," Sov. Phys. Usp., $\underline{9}, 504$ (1967).

[16] Emanuel, N. M., Denisov, E. T., and Maizus, Z. K., Liquid-phase Oxidation of Hydrocarbons, Plenum Press, NY (1967). 
[17] Vassil'ev, R. F., "On the mechanism of chemiluminescence in oxidation of organic substances and polymers," Makr. Chem., 126, 231 (1969).

[18] Belyakov, V. A., and Vassil'ev, R. F., "On some problems concerning investigation of liquid-phase chemiluminescence," Photochem. Photobiol., $\underline{\sigma}, 35$ (1967).

[19] Kellogg, R. E., "Mechanism of chemiluminescence from peroxy radicals," J. Am. Chem. Soc., 91, 5433 (1969).

[20] Beutel, J., "Chemiluminescence in oxidation reactions. The oxidation mechanism of dimedone," J. Am. Chem. Soc., 93, 2615 (1971).

[21] Howard, J. A., and Ingold, K. V., "The self-reaction of sec-butylperoxy radicals. Confirmation of the Russell mechanism," ‥ Am. Chem. Soc., $\underline{90}$, 1056 (1968).

[22] Howard, J. A., and Ingold, K. V., "Rate constants for the self-reactions of $n^{-}$and sec-butylperoxy radicals and cycloperoxy radicals. The deuterium isotope effect in the termination of secondary peroxy radicals," $\underline{J}$. Am. Chem. Soc. , 90, 1058 (1968).

[23] Vasil'ev, R. F., Vichutinskii, A. A., and Cherkasov, A. S., "Chemiluminescence activated by anthracene derivatives," Phys. Chem., 149, 203 (1963).

[24] Shmulovich, V. G., and Gol'denberg, V. I., "Chemiluminescence method for studying thermal-oxidative stability of petroleum oils," Chem. Technol. Fuel 0 ils, 13, 669 (1977).

[25] Vasil'ev, R. F., "Chemiluminescence kinetics and the study of reactions involved in the liquid-phase oxidation of hydrocarbons," Doklady Akad. Nauk. , $144,143(1962)$.

[26] Vichutinskii, A. A., "Chemiluminescence methods for determining the absolute magnitude of the rate constants for the disappearance of peroxide radicals in the liquid phase," Doklady Akad. Nauk., 157, 150 (1964).

[27] Belyakov, V. A., and Rafikova, V. S., "Determination by the method of chemiluminescence of the rate constant of quadratic recombination of peroxide radicals in reactions with a low luminescence yield," Bull. Akad. SCi. USSR, 23, 2359 (1974).

[28] Suleimanova, L. G., Suleimanova, F. G., and Zikha, V. B., "Different types of additives for motor oils studied by a chemiluminescence method, "Azerb. Khim. Zh. , (2), 71-4 (1974).

[29] Suleimanova, L. G., Suleimanova, F. G., and Ziksha, V. B., "Antioxidant additives studied by chemiluminescence," Azerb. Khim. Zh., (1) 62-5 (1973).

[30] Kuliev, A. M., Suleimanova, F. G., Gurylev, G. G., Ziksha, V. B., Suleimanova, L. G., and Abdullayev, A. M., "(1) Radiation of oxidizability of oils and oils with additives by a method of chemiluminescence. (2) Oxidizability of oils and oil additive studies by a chemiluminescent method," Lubricating $0 i 1$ Additives, publ. by Acad. Sci., Azerb., SSR, (1) NTIS AD723 151, (1971); (2) NTIS AD742 643, (1972). 
[31] Kuliyev, A. M., Suleimanova, F. G., Gurylev, G. G., Ziksha, V. B. Suleimanova, L. G., and Abdullayev, A. M., "Oxidizability of oils with additives under engine working conditions by a chemiluminescence method," Pris. K. Smaz. Mas 1., No. 2, 173-179 (1969), NTIS AD721 035, (1971).

[32] Suleimanova, G. F., Gurylev, G. G., Ziksha, V. B., Suleimanova, L. G., and Abdullayev, A. M., "Investigation of the action of organic acids on the oxidizability of mineral oils by the chemiluminescence method, "Azerb. Neft. Khozy., 47, 37-39 (1968), NTIS AD702 150, (1970).

[33] Suleimanova, G. F., Gurylev, G. G., Ziksha, V. B., Suleimanova, L. G., Abdullayev, B. I., and Abdullayev, A. M., "Chemiluminescent method for studying the thermal stability of motor oils with additives, "Azerb. Neft. Khozy, 47, 42-43 (1968), NTI AD700 374, (1969).

[34] Karpukhin, 0. N., Shlyapintokh, V. Ya., Zolotova, N. V., Kozlova, Z. G., and Rusina, I. F., "Mechanism of the weakening of chemiluminescence by inhibitors of free-radical reactions," hh. Fiz. Khim., 37, 1636 (1963).

[35] Karpukhin, O. N., Shlyapintokh, V. Ya., and Zolotova, N. V., "Chemiluminescence in inhibited oxidation reactions and the activity of inhibitors. Communication 1. Theory of chemiluminescent methods of finding the activity of inhibitors," Izvest. Akad. Nauk. SSR, Ser. Khim, No. 10, 1718-1721 (1963).

[36] Karpukhin, O. N., Shlyapintokh, V. Ya., and Zolotova, N. V., "Chemiluminescence in inhibited oxidation reactions and the activity of inhibitors. Communication 2. Measuring the activity of inhibitors by chemiluminescence methods," Izvest. Akad. Nauk. SSR, Ser. Khim, No. 10, 1722-1727 (1963).

[37] Shmulovich, V. G., and Gol'denberg, V. I., "Study of the antioxidant activity of inhibitors of the oxidation of paraffin oil hydrocarbons, "Neftekhimiya, 19, 912-20 (1979).

[38] Gol'denberg, V. I., and Shmulovich, V. G., "Study of the mechanism of chemiluminescence in the autoxidation of paraffin oil at elevated temperatures," Neftekhimiya, 19, 207-13 (1979).

[39] Gol'denberg, V. I., Shmulovich, V. G., and Yurchenko, N. I., "Chemiluminescence methods of investigating inhibited oxidation of mineral oils and fats," Petrol. Chem. USSR, 18, 166-174 (1979).

[40] Nathan, R. A., and Lundeen, G. W., paper presented at VIII Int1. Conf. Petrochem., August 1975.

[41] Nathan, R. A., "Chemiluminescence for the determination of the kinetics and mechanism of jet fuel oxidative degradation," Naval Air Systems Command, Contract N00019-73-C-0360, March 1974.

[42] Nathan, R. A., Mendenhal1, G. D., Hasse11, J. A., and Wallace, J. D., "Glowing analyses," Indus. Res., Dec. 62 (1975).

[43] Markby, R. E., Friede1, R. A., Friedman, S., and Sternberg, H. W., "Lightinduced chemiluminescence in derivatives of coal and petroleum, "Fuel, $\underline{49}, 242(1970)$. 
[44] Howard, J. A., and Ingold, K. U., "The inhibited autoxidation of styrene. Part II. The relative inhibiting efficiencies of meta- and para-substituted phenols," Can. J. Chem., 41, 1744 (1963).

[45] Shlyapintokh, V. Ya., Karpukhin, O. N., and Rusing, I. F., "Determination of the relative activities of antioxidants from the reduction in the intensity of chemiluminescence," J. Gen'1. Chem., 33, 3036 (1963).

[46] Khloplyankina, M. S., Buchachenko, A. L., Neiman, M. B., and Vasil'eva, A. G., "On the mechanism of termination of chain oxidations by radical stabilizers," Kinetika $\underline{i}$ Kataliz., $\underline{6}, 394$ (1965).

[47] Vasil'ev, R. F., and Vichutinskii, A. A., "Investigation of chemiluminescence incident to oxidation reactions in the liquid phase," Inzvest. Akad. Nauk. SSSR, Ser. Fiz., 27, 729 (1963).

[48] Zakharov, I. V., and Shlyapintokh, V. Ya., "Chemiluminescence and mechanism of the catalyzed decomposition of ethylbenzene hydroperoxide," Dokl. Akad. Nauk. SSSR, 150, 1069 (1963).

[49] Zakharov, I. V., and Shlyapintokh, V. Ya., "Chemiluminescence in slow chemical reactions $I$. Rule of chemiluminescence in the catalyzed oxidation of ethylbenzene," Kinetika i Kataliz., 4, 239 (1963).

[50] Zakharov, I. V., and Shlyapintokh, V. Ya., "Chemiluminescence in slow chemical reactions III. Chemiluminescence study of the kinetics of hydroperoxide accumulation in the catalyzed oxidation of ethylbenzene," Kinetika i Kataliz., 4, 706 (1963).

[51] Gol'dberg, V. M., and Obukhova, L. K., "On the high reactivity of peroxy radicals in oxidation-reduction reactions," Dok1. Akad. Nauk. SSSR, 155, 860 (1965).

[52] Ingold, K. U., "Inhibition of the autoxidation of organic substances in the liquid phase," Chem. Rev., 61, 563-589 (1961).

[53] Rychlá-Matisová J. L., Horanská V., and Barton, J., "Chemiluminescence on decomposition of 2,2 azobisisobutyronitrile and cumene hydroperoxide in the presence of bis(-)-ephedrine copper(II) chelate, " $\underline{\mathrm{J}}$. Luminescence, 10 , 129-136 (1975).

[54] Stieg, S., and Nieman, T. A., "Experimental and theoretical considerations of flow cell design in analytical chemiluminescence," Anal. Chem., 50, 401 (1978).

[55] Schroeder, H. R., and Volgelhut, P. 0., "Flow system for sensitive and reproducible chemiluminescence measurements," Anal. Chem., 51, 1583 (1979).

[56] Marino, D. F., and Ingle, J. D., Jr., "Microcomputer-controlled intensified diode array data acquisition system for chemiluminescence spectra," Anal. Chem. , 53, 645 (1981). 
[57] Ryan, M. A., Miller, R. J., and Ingle, J. D., Jr., "Intensified diode array detector for molecular fluorescence and chemiluminescence measurements," Anal. Chem., 50, 1771 (1978).

[58] Rychlý, J., Matisová-Rychlá, L., and Lazár, M., "A 'heterogeneous' model for oscillations of chemiluminescence in non-stationary oxidation of hydrocarbons," J. Poly. Sci., Symp. \#57, 139 (1976).

[59] Lloyd, R. A., "Apparatus for studying thermal decomposition reactions and observations on benzoyl peroxide in de-oxygenated benzene," Trans. Faraday Soc. 61,2173 (1965).

[60] Lloyd, R. A., "Low level chemiluminescence from hydrocarbon antioxidation reactions," Trans. Faraday Soc., 61, 2182 (1965).

[61] Bowen, E. J., and Lloyd, R. A., "Chemiluminescence of organic peroxide decomposition," Proc. Royal Soc., A275, 465 (1963).

[62] Belyakov, V. A., Vasil'ev, R. F., and Nalbandyan, D. M., "Chemiluminescence reactions of peroxides with armines in the presence of oxygen. I. Kinetics of the reaction of dimethylaniline with dicyclohexydperoxy dicarbonate," Kim. Vysok. Energ., 10, 238-244 (1976).

[63] Vasil'ev, R. F., and Rusina, I. F., "Mechanism of chemiluminescence in the oxidation of organic substances in solution," Dokl. Akad. Nauk SSSR, 156, 1402 (1964).

[64] Vasil'ev, R. F., and Vichutinskii, A. A., "Chemiluminescence and oxidation," Nature, 194, 1276 (1962).

[65] Vasil'ev, R. F., Karpukhin, 0. N., and Shlyapintokh, V. Ya., "Device for measuring weak light fluxes," Zhur. Fiz. Khim., 35 (1961); Russ. ‥ Phys. Chem. $\underline{35}, 223$ (1961).

[66] Vasil'ev, R. F., and Rusina, I. F., "Oxygen quenching of excited states in chemiluminescencing solutions," Dok1. Akad. Nauk SSSR, 153, 1101 (1963).

[67] Vasil'ev, R. F., "Secondary processes in chemiluminescent solutions," Nature, 196,668 (1962).

[68] Nathan, R. A., and Lundeen, G. W., "Chemiluminescence for the determination of activation energies of hydrocarbon oxidation," paper presented at the 8th International Photochemistry Conference, August, 1975.

[69] Lundeen, G. W., and Adelman, A. H., "Chemiluminescence of decomposition of 1,4 peroxy-1,4 dimethoxy-9,10 diphenylanthracene," ‥ Am. Chem. Soc., 92 , 3914 (1970).

[70] Lundeen, G. W., and Livingston, R., "Chemiluminescence of hydrocarbon oxidation," Photochem. and Photobiol., 4, 1085 (1965).

[71] Mendenha11, G. D., and Nixon, J. R., "Chemiluminescence from thermal decomposition of 1 -tetralin hydroperoxide in $\mathrm{N}$-tetradecane, " ACS Organic Preprints, \#167, Sept. 1979. 
[72] Mendenhal1, G. D., and Nathan, R. A., "Evidence from a chemiluminescence technique for bimolecular initiation in the autoxidation of tetra? in," unpublished communication.

[73] Mendenhall, G. D., and Klosterman, N. A., "Chemiluminescence from alkyl hyponitrite decomposition," paper presented at the 8th International Photochemistry Conference, August, 1975.

[74] Vichutinskii, A. A., "Novel chemiluminescence methods for determination of absolute rate constants for elementary radical reactions in the liquid phase," Nature, 206, 292 (1965).

[75] Vichutinskii, A. A., "Application of chemiluminescence to the study of some oxidation initiators," Zh. F. Khim., 38, 1666 (1964); Russ. J. Phys. Chem., 38, 908 (1964).

[76] Karpukhin, 0. N., Shlyapintokh, V. Ya., and Mikhailov, I. D., "Chemiluminescence and rates of elementary reactions in the simultaneous oxidation of cumene and ethylbenzene," Russ. ‥ Phys. Chem., 38, 81 (1964).

[77] Karpukhin, 0. N., Shlyapintokh, V. Ya., Rusina, I. F., and Zolotova, N. V., "A chemiluminescent method for determining the inhibitors of free radical reactions," Zh. Anal. Khim., 18, 1021 (1963); J. Anal. Chem. USSR, 18, 882 (1963). 
Significant Reviews on Chemiluminescence

\begin{abstract}
Author(s)/Year/Ref. Gundermann/1974/[1]
\end{abstract}

He1ler \& Richter/1974/[2]

Hercules/1970/[3]

McCapra/1973/[4]

$/ 1972 /[5]$

$/ 1970 /[6]$

Mendenha1 1/1977/[7]

Popisova, Shlyapintokh, \& Vassi]'ev/1965/[8]

Reich \& Stivala/1969/[9]

Seitz \& Neary/1977/[10]

Shlyapintokh et al./1968/ [11]
Title

Recent Advances in Research on the Chemiluminescence of Organic Compounds

Chemiluminescence in the Condensed Phase: Measurements of Rates and Yields of Excited State Formation
Subjects

Molecular mechanism of CL; Mechanism of

$\mathrm{CL}$ in $\mathrm{HC}$ autoxidation;

$C L$ from peroxide decomposition

Spectroscopy; Radiometry Instrumentation and Calibration; Measurement of absolute quantum yields

Physical Basis of Chemilumi- Molecular mechanism of CL nescence

Chemiluminescence of Organic Molecular mechanism of $\mathrm{CL}$ Compounds

Chemi 1 uminescence

The Chemiluminescence of Organic Compounds

Analytical Applications of Chemiluminescence

Chemiluminescence and the Kinetics of Chemical Reactions

Weak Chemiluminescence During Hydrocarbon Autoxidation

Chemiluminescence and Bioluminescence Analys is

Chemiluminescence Techniques in Chemical Reactions
Molecular mechanism of $\mathrm{CL}$

$\mathrm{CL}$ from singlet oxygen

$C L$ from peroxide decomposition

Instrumentation; $\mathrm{CL}$ in hydrocarbon oxidation; $\mathrm{CL}$ analysis of complex materials; Correlation with stability; service life

$C L$ in hydrocarbon oxidation: kinetics; inhibitors; catalysts

$\mathrm{CL}$ in hydrocarbon oxidation: kinetics; inhibitors; catalysts

$C L$ in evaluation of material degradation; Instrumentation

Instrumentation; $\mathrm{CL}$ in hydrocarbon oxidation: kinetic methods; inhibitors; catalysts 
Free Radicals and Chemi-

luminescence

Chemiluminescence Excitation Molecular mechanism of $\mathrm{CL}$ Mechanisms

$/ 1967 /[14]$

$/ 1967 /[15]$
$C L$ in hydrocarbon oxidation: inhibitors; kinetic methods

$\mathrm{CL}$ in hydrocarbon oxidation; Kinetic methods

Molecular mechanism of $\mathrm{CL}$
Chemiluminescence in Liquidphase Reactions

Chemiluminescence in Solutions 
Table 2

Summary of Chemiluminescence Kinetic Methods

Method

Induction time

Onset temperature

Activation energy

Oxygen drop

Dilution oxygen drop

Non-steady state
Use

Antioxidant evaluation

Oxidation stability

$E_{\text {Act }}$ for initiation

or propagation reactions

Overall oxidation rate

Rate constant ratios

Absolute rate constants
Conditions

Constant temperature

Slow temperature scan

Arrhenius treatment of $t_{\frac{1}{2}}$ or $I_{\text {max }}$, respectively

Shut off $\mathrm{O}_{2}$ at a constant temperature and monitor $I_{C L}$ vs $t$

Vary conc'n (must know $\left[\mathrm{O}_{2}\right]$ or initial rate, $w_{i}$ )

Abrupt change in $\mathrm{O}_{2}$ introduction or $w_{i}$ 


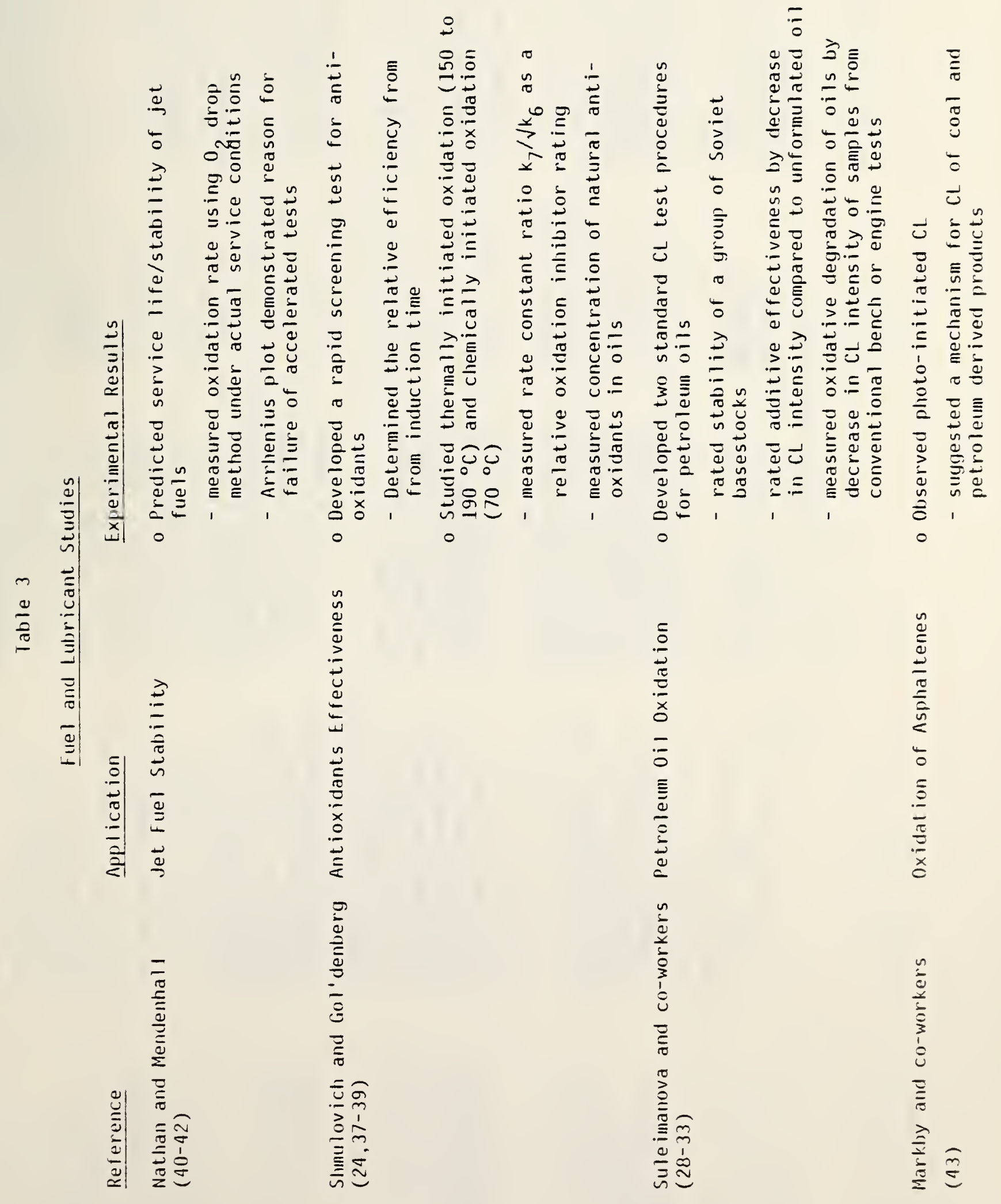



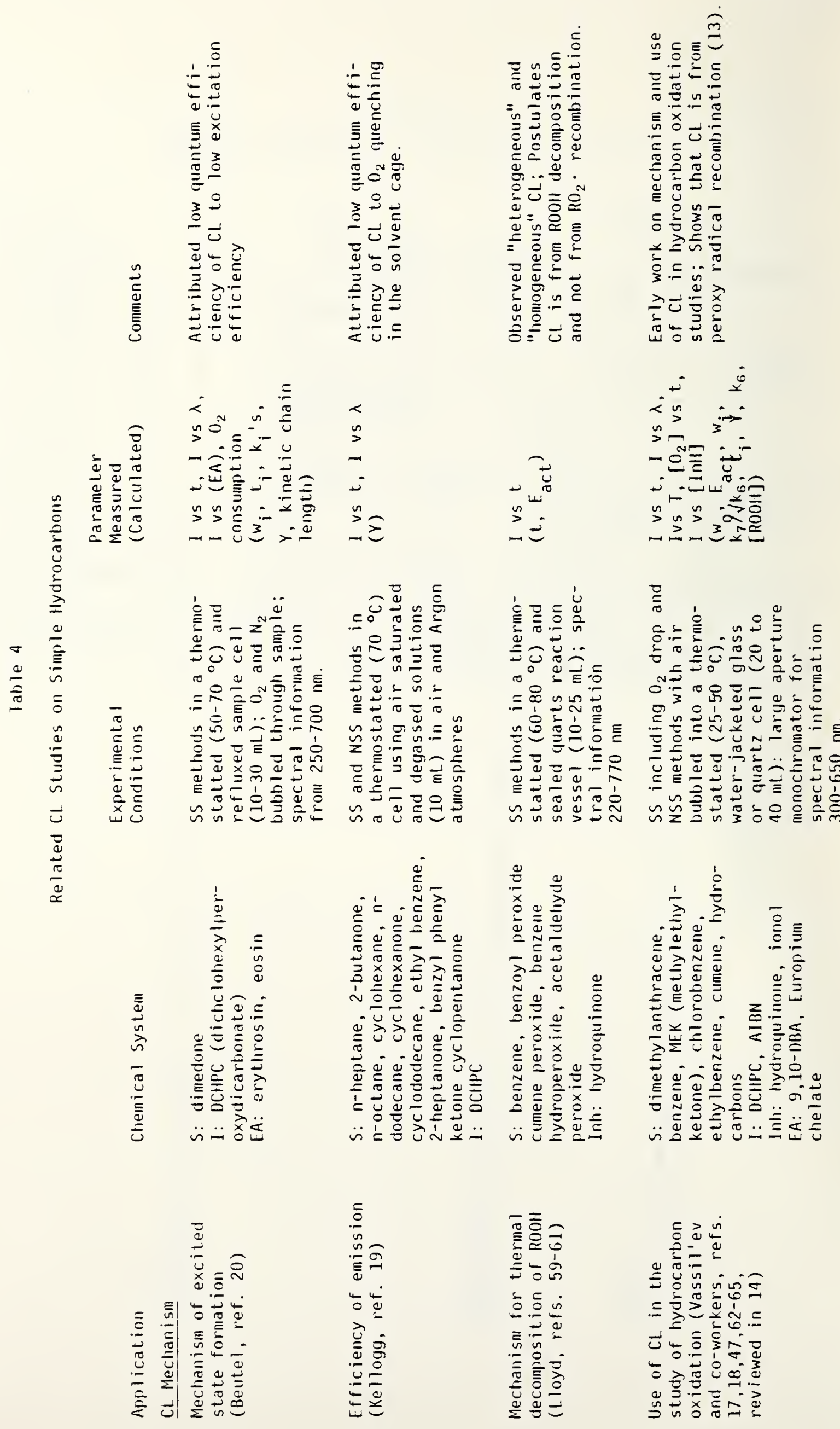


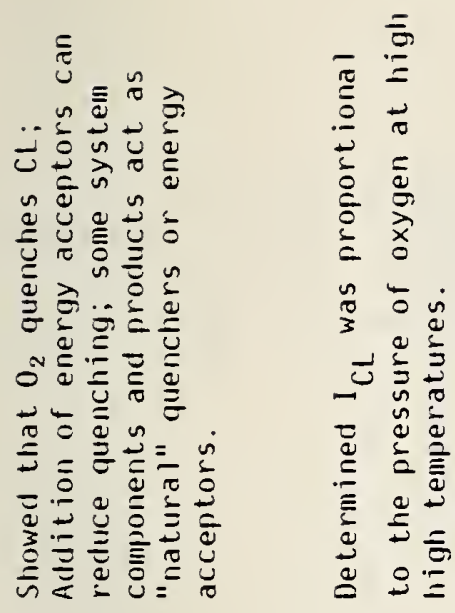

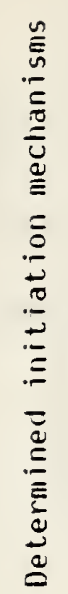

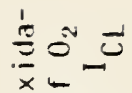

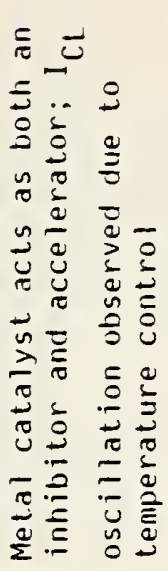

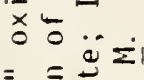

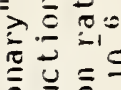

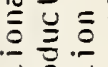

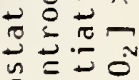

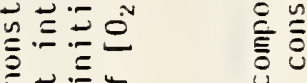

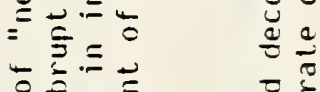

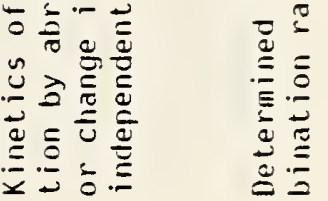
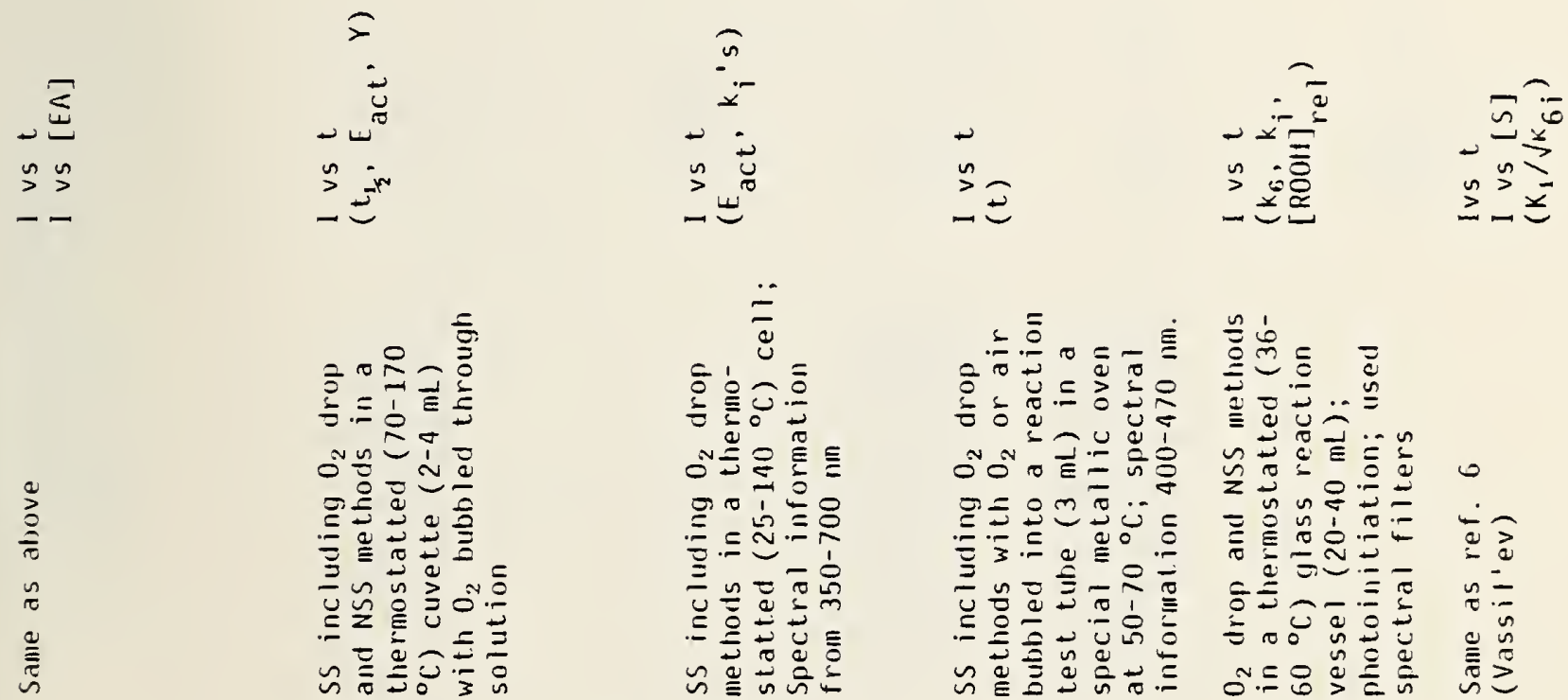

$\frac{\sqrt[1]{x}}{\stackrel{2}{2}}$

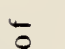

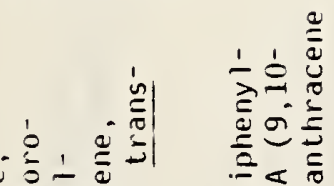

$\stackrel{n}{2}$ a

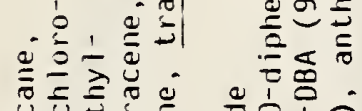

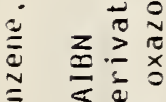
造.

$\overline{0} \div \frac{\stackrel{0}{0}}{0}$ 1
$\vdots$
$\vdots$
0
0
0
$\vdots$
$\vdots$
0

$\frac{1}{2}$

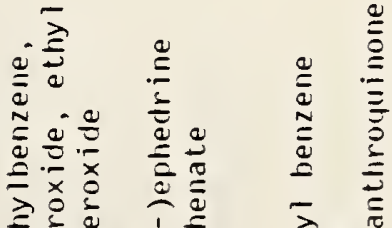

$\simeq \stackrel{9}{\circ}$.

事

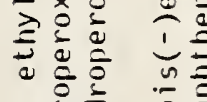

赔衣

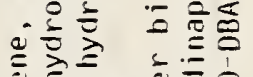

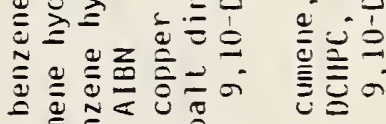

을 它

$\ddot{\sim} \ddot{\ddot{\Xi}}$

$\frac{1}{3}$

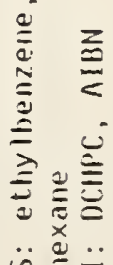

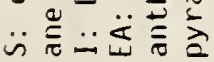

$\bar{c}$

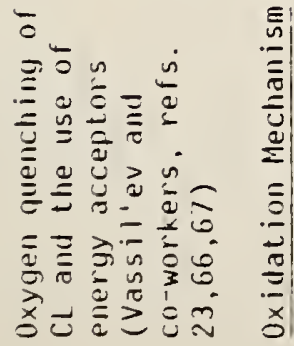

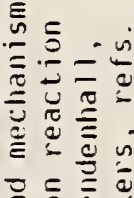

ํㅗㅎำ

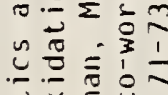

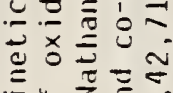

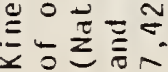

岳

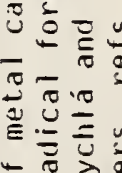

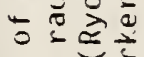

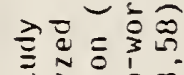

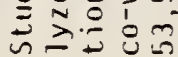

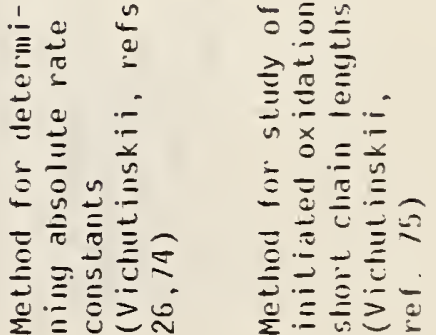




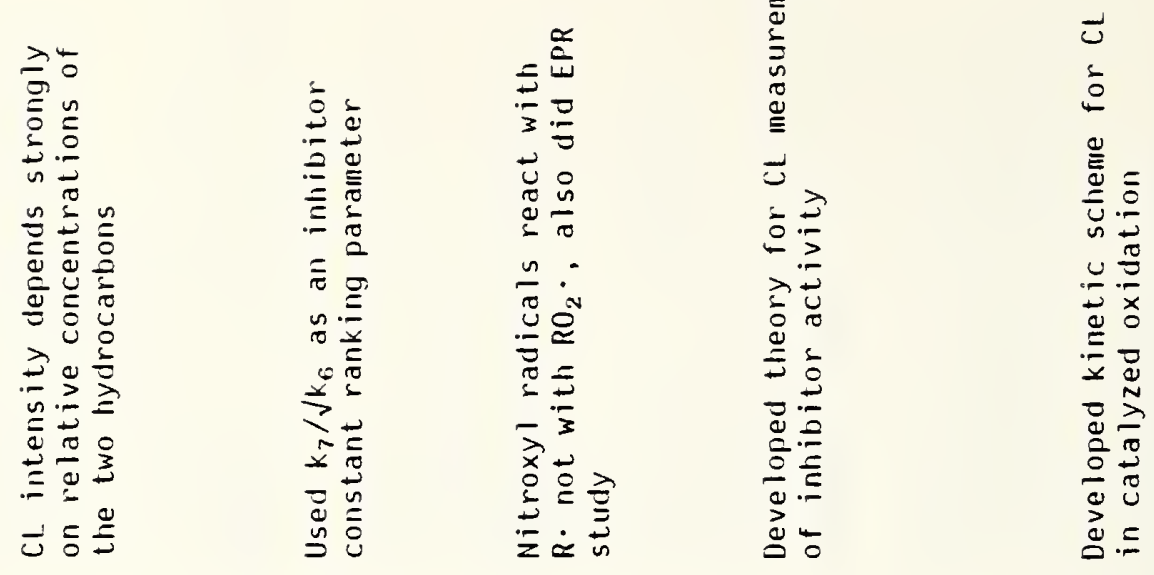
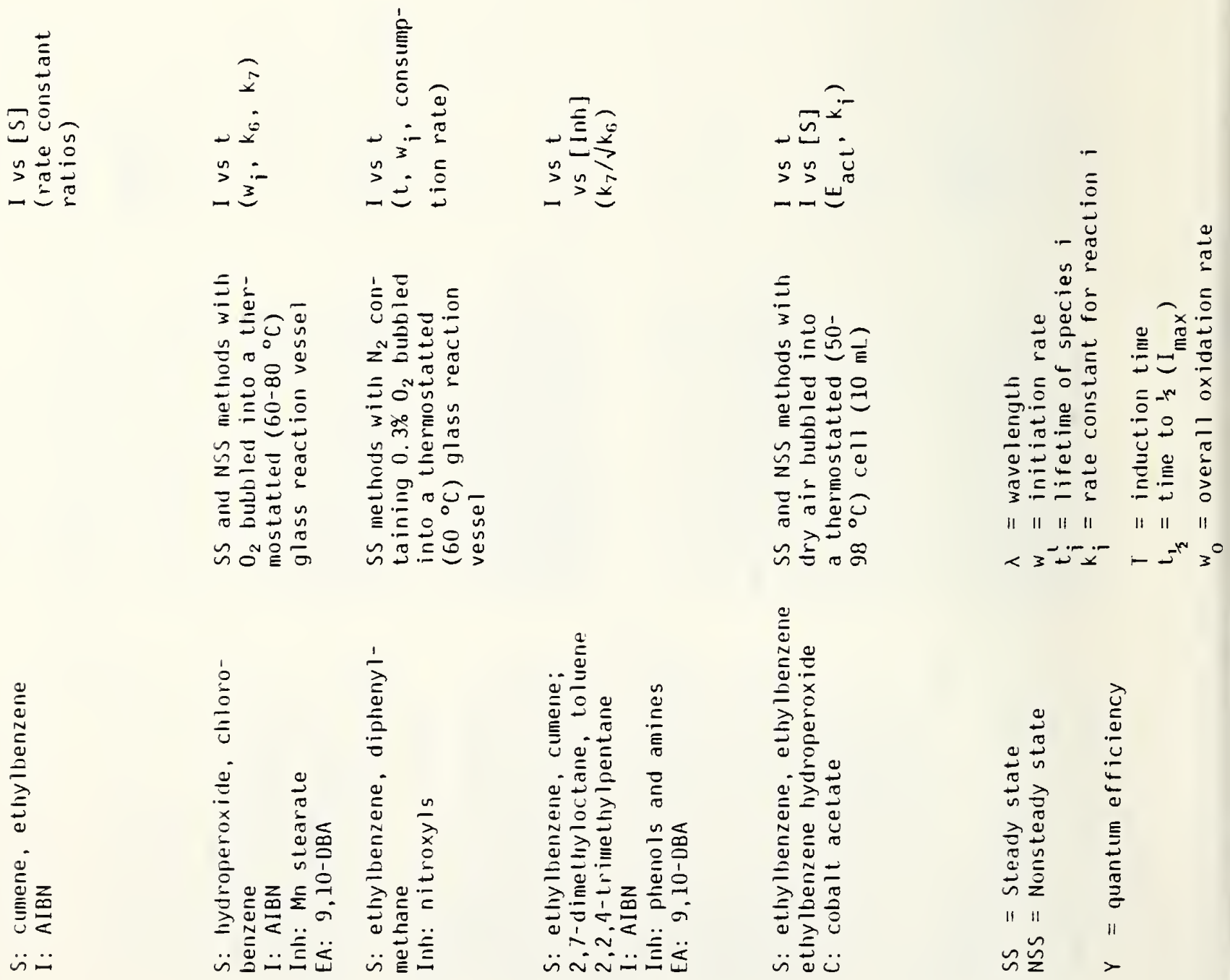

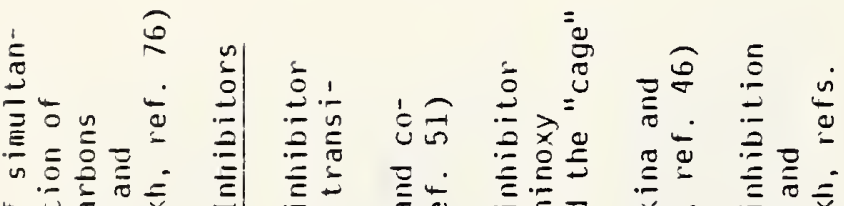

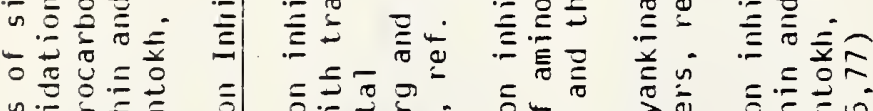

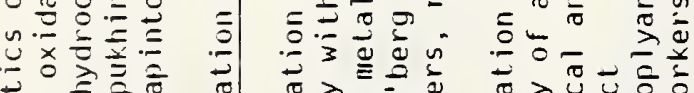

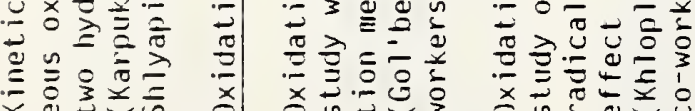

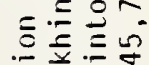

范

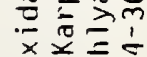

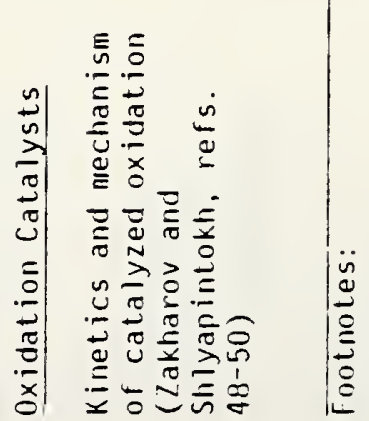

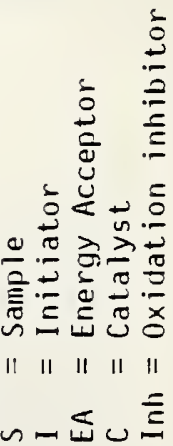


Figure Captions

Figure 1. Typical intensity-time plot for $C L$ oxygen drop experiment

Figure 2. Basic chemiluminescence apparatus 


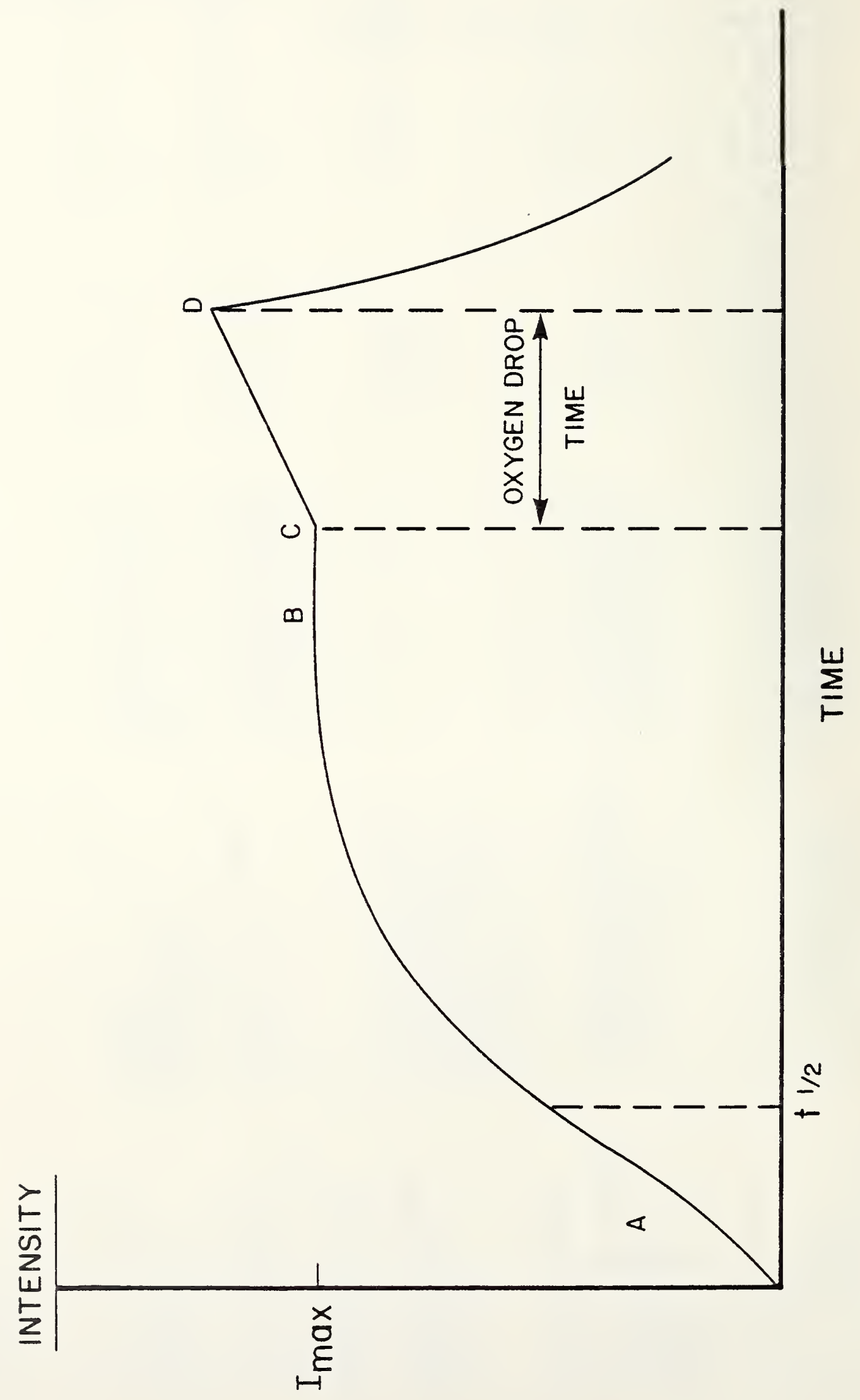




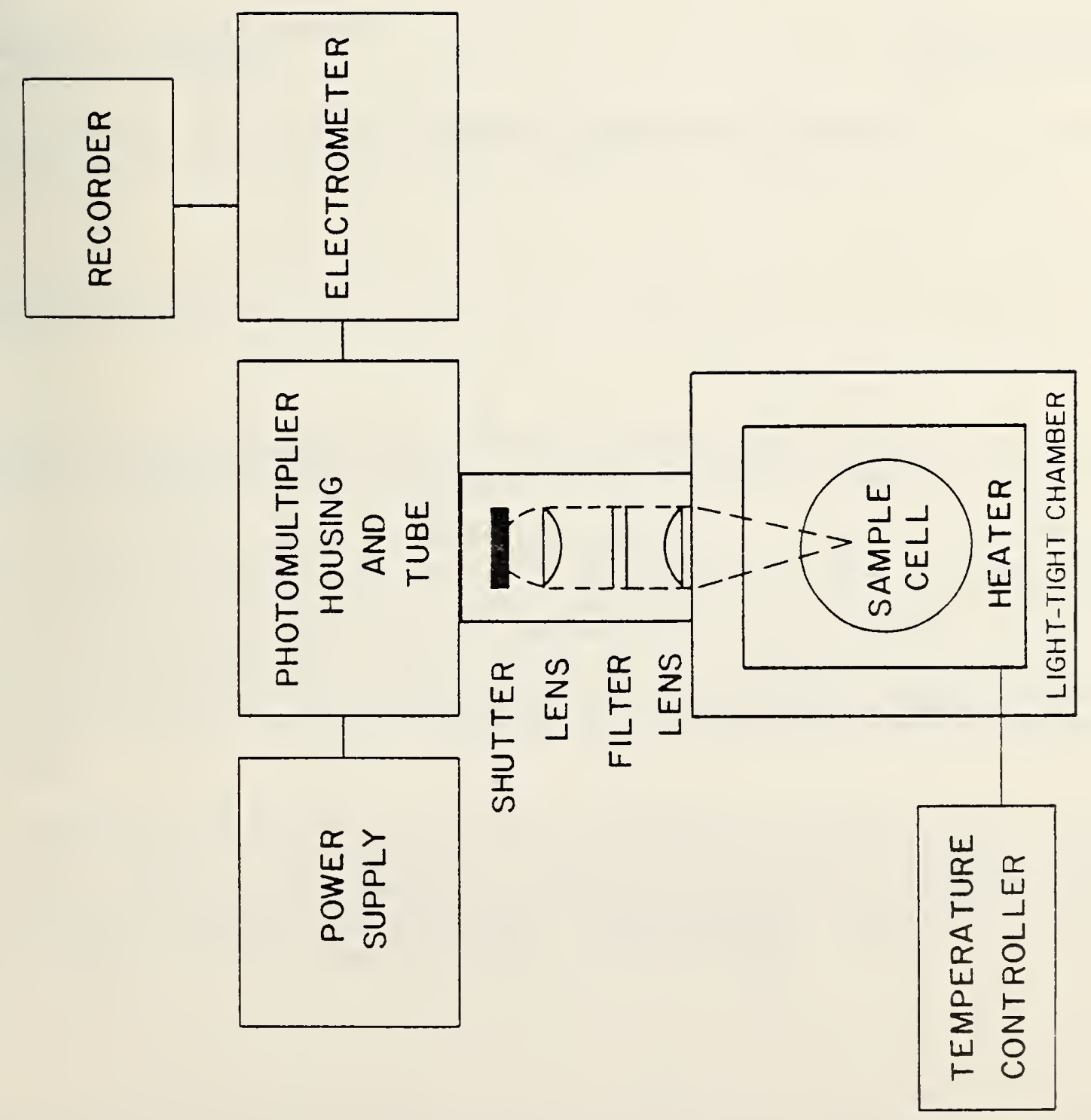



4. TITLE AND SUBTITLE

An Introduction to Chemiluminescence Methods for Lubricant Oxidation Studies

5. $A \cup T H O R(S)$

D.B. Clark, S. J. Weeks and S. M. Hsu

6. PERFORMING ORGANIZATION (If joint or other than NBS. see instructions)

7. Contract Grant No.

NATIONAL BUREAU OF STANDARDS

DEPARTMENT OF COMMERCE

WASHINGTON, D.C. 20234

9. SPONSORING ORGANIZATION NAME AND COMPLETE ADDRESS (Street. City. State. ZIP)

8. Type of Report \& Period Covered

10. SUPPLEMENTARY NOTES

Document describes a computer program; SF-185, FIPS Software Summary, is attached.

11. ABSTRACT (A 200-word or less factual summary of most significant information. If document includes a significant bibliography or literature survey, mention it here)

An introductory review of chemiluminescence $(C L)$ techniques describes applications for the study of oxidation of fuels and lubricants. Reviews of chemiluminescence and oxidation are briefly discussed. The mechanism of $\mathrm{CL}$ as it applies to complex hydrocarbon systems is discussed. Several steady state and nonsteady state kinetic methods are discussed with respect to the ability of each technique to give useful information about the kinetics and mechanisms of oxidation. Applications of $\mathrm{CL}$ techniques for fuels and lubricants, as well as simple hydrocarbon systems, are discussed.

The unique properties of $\mathrm{CL}$ methods for materials testing (e.g. Tubricant oxidation stability)as well as fundamental understanding of chemical oxidation reactions are emphasized. Studies which evaluate petroleum and synthoil products, oxidation inhibitors and metal catalysts are discussed. Instrumentation capabilities are reviewed and critical features of instrumental design are discussed.

12. KEY WORDS (Six to twelve entries: alphabetical order; capitalize only proper names; and separate key words by semicolons) additives; antioxidants; basestocks; chemiluminescence; fuels; hydrocarbons; review; kinetic methods; lubricating oils; materials testing; oxidation; petroleum products; 


